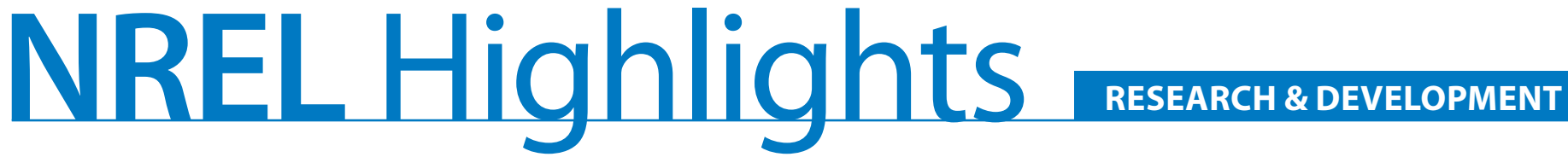

\section{NREL Technical Reports Guide the Way to $50 \%$ Energy Savings in Hospitals, Office Buildings}

Using existing technologies, designers and operators of large buildings could slash national energy use across a broad range of climates.

Researchers at the National Renewable Energy Laboratory (NREL) have developed two technical reports that provide recommendations to help designers and operators of large office buildings and hospitals achieve at least a 50\% energy savings using existing technology.

Strategies for 50\% Energy Savings in Large Office Buildings found that a 50\% energy savings can be realized in both low- and high-rise office buildings in a broad range of U.S. climates. Large Hospital 50\% Energy Savings details how energy savings from $50.6 \%$ to $61.3 \%$ can be attained in large hospitals across all eight U.S. climate zones.

To reach these energy efficiency goals, both studies recommended implementing numerous energy saving techniques, such as:

- Reducing lighting power density and using occupancy and daylight sensors;

- Installing high-efficiency boilers, chillers, and air distribution units; and

- Reducing plug loads by purchasing high-efficiency electronic equipment and using special controls that shut off equipment when not in use.

Conducted by NREL's Commercial Buildings Group, under the direction of U.S. Department of Energy's (DOE) Building Technologies Program, the studies support the DOE goal of significantly improving the energy efficiency of new and existing commercial buildings across the United States.

In many cases, technical support documents such as these are the basis for ASHRAE's Advanced Energy Design Guides, which are "how-to" guides that show architects, engineers, and building designers how to achieve better-than-code energy performance for buildings using existing technologies.

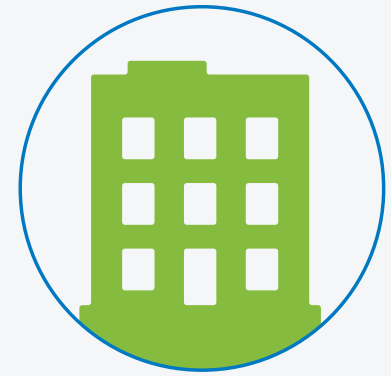

\section{Key Research Results}

Achievement

NREL's Commercial Buildings Group developed two technical reports that provide recommendations on how to achieve $50 \%$ energy savings in large office buildings and hospitals.

Result

The report found that at least a 50 -percent energy savings can be achieved in both low- and high-rise office buildings as well as large hospitals in a broad range of U.S. climates.

Potential Impact

These "how-to" guides will help architects, engineers, and building designers achieve better-than-code exemplary energy performance for buildings using existing technologies. 